Brazilian Journal

of Chemical

Engineering

\title{
POLYETHERIMIDE/POLYVINYLPYRROLIDONE HOLLOW-FIBER MEMBRANES FOR USE IN HEMODIALYSIS
}

\author{
Alana M. dos Santos ${ }^{1 *}$, Alberto C. Habert ${ }^{1}$ and Helen C. Ferraz ${ }^{1}$ \\ ${ }^{1}$ Universidade Federal do Rio de Janeiro, Programa de Engenharia Química, Rio de Janeiro, RJ, Brasil. E-mail: alana.melo0205@gmail.com - \\ ORCID: 0000-0002-7317-4816; ORCID: 0000-0003-0482-5475; ORCID: 0000-0002-6058-5296
}

(Submitted: November 6, 2018 ; Revised: April 4, 2019 ; Accepted: May 15, 2019)

\begin{abstract}
In this study, polyetherimide/polyvinylpyrrolidone (PEI/PVP) hollow fiber membranes (HFMs) were synthesized by the phase inversion method. The synthesized PEI/PVP membranes were characterized by morphological analysis and transport properties (hydraulic permeability and solute rejection coefficient). Their performance in uremic solutes separation was also investigated. Urea removal and clearance were measured. Surface properties were analyzed by infrared spectroscopy (FT-IR), water uptake, zeta potential and protein adsorption. The results showed that PEI/PVP membranes had transport properties comparable to those of current high flux clinical membranes, with better removal of medium molecular weight solutes (using lysozyme as a model) and high retention of high molecular weight solutes (using albumin as a model). Surface characterization suggests that PEI/PVP membranes present improved blood compatibility. These results confirm the potential of polyetherimide as an alternative material for producing hollow fiber hemodialyzers, in substitution to polysulfone and polyethersulfone.

Keywords: Hollow fiber; Polyetherimide; Polyvinylpyrrolidone; Hemodialysis.
\end{abstract}

\section{INTRODUCTION}

Hemodialysis is a consolidated renal replacement therapy that uses a dialyzer to remove excess substances from the blood in the treatments for chronic kidney disease. The dialyzer cartridge is a packing of hollow fiber membranes, fabricated mostly from polymer blends. According to Stamatialis et al. (2008), hemodialysis membranes must present some specific characteristics, such as having a thin effective layer of separation, to obtain high flows of solutes; high porosity, to provide high hydraulic permeability; and a narrow distribution of pore size, to obtain a better defined retention limit. Synthetic materials used for the fabrication of hemodialysis membranes are polysulfone, polycarbonate, polyethylene, polypropylene, polyethersulfone, polymethylmethacrylate and polyacrylonitrile.
Hemodialysis treatment allows chronic kidney patients to have a life close to normal. However, the treatment still has some limitations such as the low removal rate of medium sized molecules, such as $\beta_{2}$-microglobulin. Its accumulation in the blood is associated with the occurrence of amyloidosis and carpal tunnel syndrome (Wechs et al., 2014).

This investigation aims at the synthesis and characterization of polyetherimide/ polyvinylpyrrolidone (PEI/PVP) membranes for application in hemodialysis, with improved removal of medium molecules as compared to the current clinical membranes. Polyetherimide (PEI) membranes are not common in hemodialysis, however they do show interesting characteristics for this application, such as mechanical strength and thermal stability, processability in different forms and suitability for a wide range of surface modifications (Santos et al., 2017).

\footnotetext{
*Corresponding author: Alana M. dos Santos - E-mail: alana.melo0205@gmail.com
} 


\section{MATERIALS AND METHODS}

\section{Materials}

Polyetherimide (PEI Ultem 1000, General Eletric), N-methyl-2-pyrrolidone (NMP, Vetec) and polyvinylpyrrolidone (PVP K90, Fluka Chemica Co) were used for membrane synthesis. Membrane rejection to the following compounds was evaluated: urea (Reag Quimibrás), creatinine (Merk), monobasic sodium phosphate (Vetec), dibasic sodium phosphate (Vetec), vitamin B12 (Merk), lysozyme (SigmaAldrich) and bovine serum albumin (BSA, SigmaAldrich). Potassium chloride (Sigma-Aldrich) and hydrochloric acid (Sigma-Aldrich) were used in zeta potential analysis.

\section{Synthesis of polyetherimide membranes}

Hollow fiber membranes were synthesized through the single extrusion of a spinning solution composed of 15 wt.\% PEI, 05 wt.\% PVP and 80 wt.\% NMP through an annular orifice towards the external precipitation bath, composed by microfiltered water at $25^{\circ} \mathrm{C}$. The bore liquid, a solution composed of microfiltered water and NMP $(1: 1 \mathrm{v} / \mathrm{v})$, is pumped toward the spinneret to form the fiber lumina and it is co-extruded through an inner orifice. The water content of the polymers was dried by heating in an oven for $24 \mathrm{~h}$ at a temperature of $60^{\circ} \mathrm{C}$. The contact of the two liquid phases occurs at the exit of the extruder and allows the initial formation of the hollow fiber. At the exit from the precipitation bath, the fibers were collected in another microfiltered water bath to remove residual solvent present in the polymer matrix. Figure 1 shows a scheme of the hollow fiber synthesis system by extrusion.

The fibers were kept immersed in microfiltered water and oven-heated at $60{ }^{\circ} \mathrm{C}$ for 24 hours for complete removal of residual solvent. Thereafter, the fibers were dried at room temperature after being immersed in a water bath and glycerol $(10: 1 \mathrm{v} / \mathrm{v})$ for 4 hours.

After drying the fibers, permeation modules of approximately $60 \mathrm{~cm}^{2}$ were prepared to be used

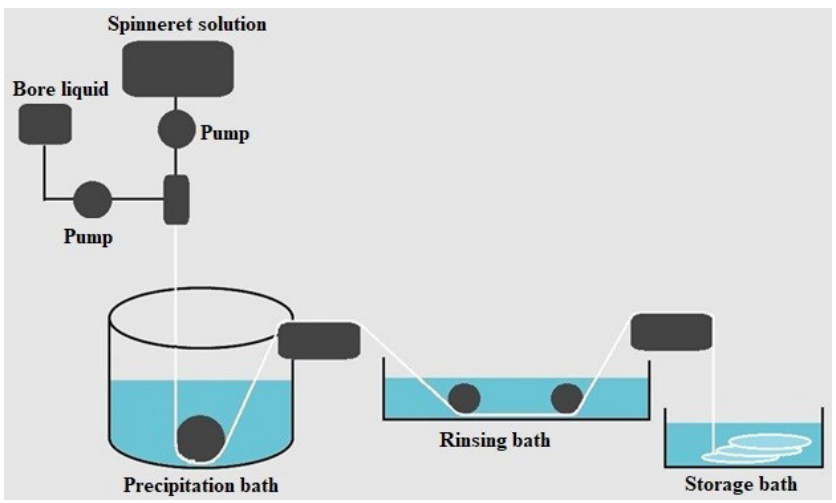

Figure 1. Scheme of the fiber synthesis equipment by extrusion of the polymer solution. in performance tests. In addition, permeation modules with the same area were prepared using polyethersulfone (Clinical PES, a Baxter dialyzer) and polysulfone (Clinical PSf, a Fresenius Medical Care dialyzer) clinical membranes.

\section{Morphological analysis}

Morphological analysis was performed using a scanning electron microscope (FEI Quanta 200). Membrane samples were previously coated with gold under vacuum in a sputtering system (Quorum Q150RES). To allow observation of the cross-sections of the membrane, samples were immersed in liquid nitrogen and carefully fractured.

\section{Transport properties}

The hydraulic permeability was obtained through ultrafiltration tests (Figure 2) at room temperature and using the correlation of the permeate flux with pressure, according to Equation (1). In the ultrafiltration tests, the feed was pumped into the fiber lumen, keeping the lower end closed and collecting permeate from the exit of the permeation module. The system was operated continuously, recycling part of the feed pumped into the fibers, and adjusting the pressure through a regulating valve. The pressure ranged from 0.4 to 1 bar.

$\mathrm{J}=\mathrm{L}_{\mathrm{p}} \Delta \mathrm{P}$

where $J$ is the water flux $(\mathrm{L} / \mathrm{h}), \mathrm{L}_{\mathrm{P}}$ is the hydraulic permeability $\left(\mathrm{L} / \mathrm{h} \cdot \mathrm{m}^{2} \cdot\right.$ bar $)$ and $\Delta \mathrm{P}$ is the pressure difference between feed solution and the permeate (bar).

Solute rejection coefficients of uremic solutes (urea, creatinine, phosphate, vitamin B12, lysozyme and albumin) was also determined through ultrafiltration tests at room temperature. Lysozyme is a protein with a molar mass of $14.3 \mathrm{kDa}$, used in experiments as a substitute model for $\beta_{2}$-microglobulin, a $11.8 \mathrm{kDa}$ macromolecule. The rejection coefficient was obtained using Equation (2).

$\mathrm{R}(\%)=\frac{\left(\mathrm{C}_{\mathrm{A}}-\mathrm{C}_{\mathrm{P}}\right)}{\mathrm{C}_{\mathrm{A}}} \times 100$

where $\mathrm{C}_{\mathrm{A}}$ is the feed concentration and $\mathrm{C}_{\mathrm{P}}$ is the permeate concentration.

The choice of the initial concentration of the solutes was based on their concentration in blood, according to international standard requirements for hemodialysers (ISO 8637:2010). Accordingly, concentrations of urea, creatinine and phosphate were set at $30.0 \mathrm{mmol} / \mathrm{L}, 0.94 \mathrm{mmmol} / \mathrm{L}$ and 1.7 $\mathrm{mmol} / \mathrm{L}(\mathrm{pH}$ 7.4), respectively. Phosphate solution 


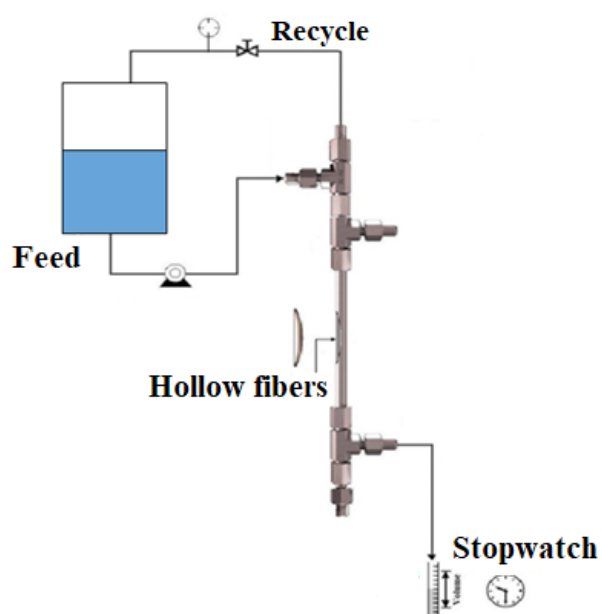

Figure 2. Ultrafiltration system.

consisted of monobasic sodium phosphate and dibasic sodium phosphate. Concentrations of solutes were determined by assay kits provided by Katal (Brazil) to determine urea and creatinine concentration; and by Doles Reagents (Brazil), to determine phosphate concentration. Lysozyme and albumin concentrations were $90 \mathrm{mg} / \mathrm{L}$ and $1000 \mathrm{mg} / \mathrm{L}$, respectively, and their concentration was determined by spectrophotometry. The same tests were also performed for clinical PSf and clinical PES membranes.

\section{Urea removal and clearance}

Urea removal and clearance were determined through dialysis tests carried out for 4 hours. An aqueous solution of urea at $1800 \mathrm{mg} / \mathrm{L}$, was fed into the fibers. Demineralized water, acting as dialysate, was fed between the module shell and the fibers, according to the scheme shown in Figure 3.

Feed and dialysate samples were collected at the beginning and at the end of the test. The feed rates were maintained at around $225 \mathrm{~mL} / \mathrm{min}$ and dialysate at $450 \mathrm{~mL} / \mathrm{min}$. In tests performed with the membranes of clinical dialyzers (PSf and PES membranes), the maximum feed rates reached were $25 \mathrm{~mL} / \mathrm{min}$, while the dialysate flow rate was twice that value.

Urea removal was determined from the final dialysate concentration (after 4 hours) and from the initial concentration of the feed solution through Equation (3).

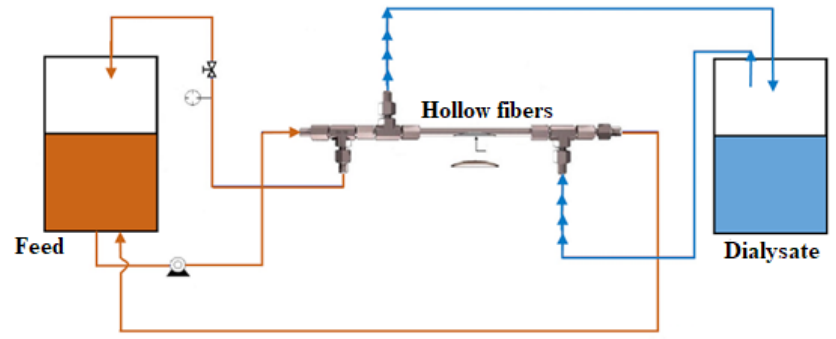

Figure 3. Dialysis system.
$\mathrm{UR}(\%)=\left(1-\frac{\mathrm{C}_{\mathrm{UF}}}{\mathrm{C}_{\mathrm{UI}}}\right) \times 100$

where UR is the urea removal, $\mathrm{C}_{\mathrm{UF}}$ is the concentration of post-dialysis urea and $\mathrm{C}_{\mathrm{UI}}$ is the concentration of pre-dialysis urea.

The urea clearance was calculated using the definition of diffusive clearance, according to Equation (4):

$\mathrm{K}=\frac{\mathrm{Q}_{\mathrm{Di}} \mathrm{C}_{\mathrm{Do}}}{\mathrm{C}_{\mathrm{Bi}}}$

where $\mathrm{K}$ is the clearance of urea $(\mathrm{mL} / \mathrm{min}), \mathrm{Q}_{\mathrm{Di}}$ is the flow rate of dialysate $(\mathrm{mL} / \mathrm{min}), \mathrm{C}_{\mathrm{Do}}$ is the final concentration of urea in the dialysate $(\mathrm{mg} / \mathrm{L})$ and $\mathrm{C}_{\mathrm{Bi}}$ is the inicial concentration of urea in the feed $(\mathrm{mg} / \mathrm{L})$.

\section{Surface characterization}

Hollow fiber membranes were characterized by Fourier transform infrared spectra with attenuated total reflectance using the ATR-FTIR, PerkinElmer Spectrum 100 spectrometer. Spectra were recorded between 500 and $4000 \mathrm{~cm}^{-1}$, using 16 scans for each sample, which was placed under the crystal on only one side.

\section{Hydrophilicity}

The hydrophilicity of the membranes was evaluated by water absorption. An amount of dry membrane, defined as $\mathrm{m}_{1}$, was immersed in demineralized water for 8 hours at $25^{\circ} \mathrm{C}$. After this time, the membrane was dried to remove excess water on the surface, weighed and its new weight was defined as $\mathrm{m}_{2}$. The water absorption was determined by Equation (5) and given in $\mathrm{mg}$ water/ mg membrane.

Water absorption $=\frac{m_{2}-m_{1}}{m_{1}}$

\section{Zeta potential}

Measurements of zeta potential were performed on the SurPass equipment (Anton Paar, Austria), based on the electrokinetic phenomenon of streaming potential. In this equipment, recirculated diluted electrolytic solution (potassium chloride, $1 \mathrm{mM}$ ) through a channel formed by a spacer between two identical membrane samples, arranged one opposite to another, according to Equation (6) (Hurwitz et al., 2010):

$$
\left(\frac{\Delta \varphi}{\Delta \mathrm{P}}\right)=\varsigma \frac{\varepsilon_{0} \varepsilon_{\mathrm{r}}}{\eta \lambda_{\mathrm{o}}}\left(\frac{\lambda_{\mathrm{h}} \mathrm{R}_{\mathrm{h}}}{\mathrm{R}}\right)
$$


where $\Delta \varphi$ is the flow potential $(\mathrm{mV}), \Delta \mathrm{P}$ is the pressure applied in the cell to force the electrolyte to flow over the charged surface (mbar), $\varepsilon_{0}$ is the vacuum permittivity $(\mathrm{As} / \mathrm{Vm}), \varepsilon_{\mathrm{r}}$ is the relative dielectric constant of the solvent of the electrolyte, $\varsigma$ is the zeta potential $(\mathrm{mV})$, $\eta$ is the dynamic viscosity of the electrolyte (mPa.s), $\lambda_{0}$ is the electrical conductivity of the circulating electrolyte $(\mathrm{mS} / \mathrm{m}), \lambda_{\mathrm{h}}$ is the electrical conductivity of the electrolytic solution $(\mathrm{mS} / \mathrm{m}), \mathrm{R}_{\mathrm{h}}$ is the electrical resistance measured through the flow channel and $\mathrm{R}$ is the electrical resistance measured through the channel under normal experimental conditions.

Prior to the analysis, membranes were immersed in $1 \mathrm{mmol} / \mathrm{L}$ potassium chloride solution. Each measurement was performed in the approximate $\mathrm{pH}$ range of 2 to 6 , starting from the most basic $\mathrm{pH}$ to the most acidic $\mathrm{pH}$.

\section{Protein adsorption}

Albumin adsorption on the hollow fiber surface was determined by the static mode (finite bath method). A known membrane amount (approximately $50 \mathrm{mg}$ ) was packed in glass tubes containing $10 \mathrm{~mL}$ of $40 \mathrm{mg} / \mathrm{L}$ bovine albumin solution and agitaded in a shaker at room temperature for 4 hours, the average time of a hemodialysis session. The concentrations of the albumin solutions were determined at the beginning and after contact with the membranes by spectrophotometry, reading the absorbance at $278 \mathrm{~nm}$ and correlating with the pre-determined calibration curve.

The amount of albumin adsorbed, in mg of albumin per mg of membrane, was determined by concentration difference, according to Equation (7):

Pr otein adsorption $=\left(\frac{\mathrm{m}_{\mathrm{i}}-\mathrm{m}_{\mathrm{f}}}{\mathrm{m}_{\text {membrane }}}\right)$

where $m_{i}$ is the initial quantity of albumin in solution, $\mathrm{m}_{\mathrm{f}}$ is the quantity of albumin in solution after the time of contact with the membrane and $\mathrm{m}_{\text {membrane }}$ is the quantity of membrane packed in glass tubes.

This test was also performed for clinical PSf and clinical PES membranes.

\section{RESULTS}

\section{Morphological analysis}

Scanning electron microscopy (SEM) observations of the cross sections (CS) and the external (ES) and internal (IS) surfaces of the HFMs are shown in Figure 4.

It can be seen that the hollow fibers synthesized from a spinning solution composed by $15 \mathrm{wt} . \% \mathrm{PEI}, 05$ wt.\% PVP e 80 wt.\% NMP have a typical asymmetric
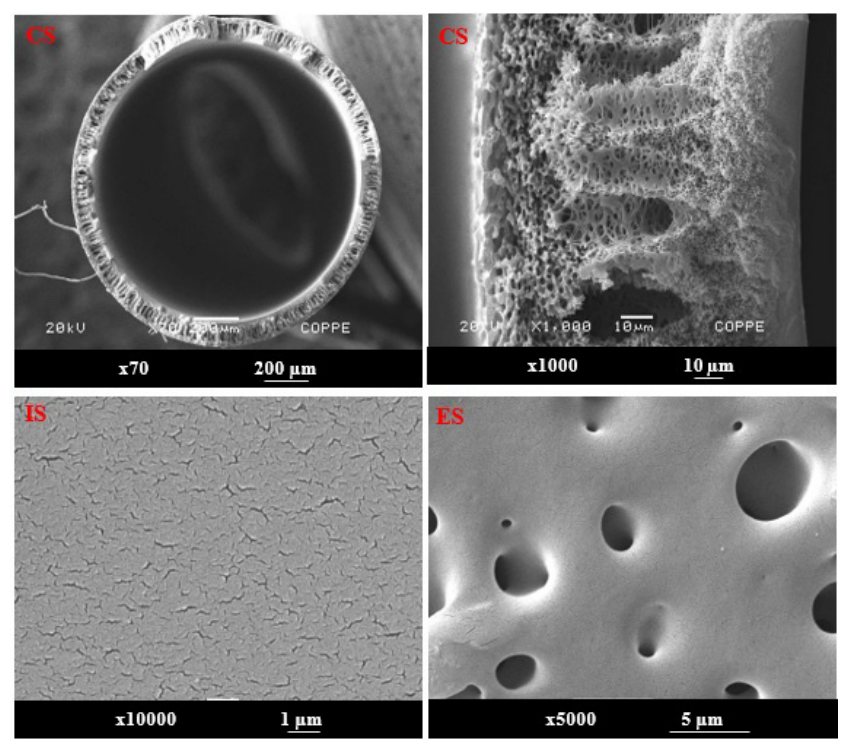

Figure 4. SEM images of PEI/PVP hollow fiber membranes. CS is cross section, IS is internal surface and ES is external surface.

structure, characterized by a less porous top surface and a highly porous sublayer with interconnected pores. It is possible, however, to observe pores on the inner surface of the hollow fibers, which is related to the presence of solvent in the bore liquid. In this case, the nuclei have more time to grow because a delay in precipitation occurs on the internal surface of membranes. Therefore, pores can be formed in this surface (Pereira et al., 2000). From the image of the hollow fiber cross section, it was also possible to obtain its dimensions in relation to the external diameter $(1.35 \pm 0.03 \mathrm{~mm})$ and wall thickness $(100$ $\pm 18.84 \mu \mathrm{m})$. Clinical PES membranes have $0.26 \pm$ $0.01 \mathrm{~mm}$ of external diameter and $28.43 \pm 1.16 \mu \mathrm{m}$ of wall thickness and clinical PSf membranes have 0.28 $\pm 0.01 \mathrm{~mm}$ of external diameter and $49.77 \pm 3.70 \mu \mathrm{m}$ of wall thickness.

In general, the final morphology of the synthesized hollow fibers composed of a densified inner surface and a porous outer surface is similar to the morphology of clinical hemodialysis membranes, as can be seen in Figure 5.

\section{Transport properties}

The results of transport properties of HFMs are shown in Table 1. Retention was not observed of the solutes urea, creatinine, phosphate and vitamin $B_{12}$, so membranes presented $0 \%$ rejection coefficient of these solutes. These results indicate that the synthesized hollow fibers membranes allow the passage of the low molecular weight solutes, as desired.

Synthesized hollow fiber membranes can be classified as a high flux membrane, like the clinical PES membrane, according to the classification proposed by Ward (2005). High-flux membranes are 

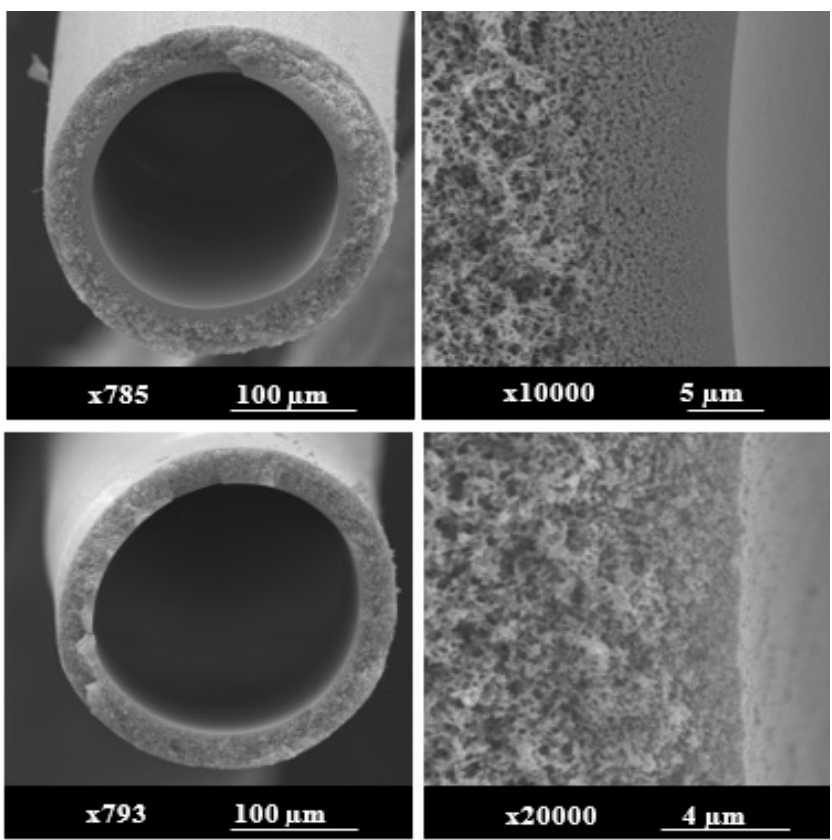

Figure 5. SEM images of hemodialysis clinical hollow fiber membranes (a) PSf and (b) PES.

the most used in hemodialysis treatments, since they generally show higher clearances of low molar mass solutes, better removal of medium-sized molecules, and are associated with the potential reduction of morbidity and increase in survival rates (Boué and Vanholder, 2004; Oshvandi et al., 2014; Tan et al., 2018). In addition, high permeability membranes are indicated for the hemofiltration and hemodiafiltration treatments, which have gained space in dialysis clinics (Nubé et al., 2016; Maduell et al., 2017; Tan et al., 2018).

In a previous work of this lab (Santos et al., 2017), flat sheet membranes for hemodialysis based on polyetherimide (PEI) and polyvinylpyrrolidone (PVP) were produced, with chemical immobilization of heparin on its surface in order to increase blood compatibility. The authors observed that hydraulic permeability was $44.3 \mathrm{~L} / \mathrm{h} \cdot \mathrm{m}^{2}$.bar, which is comparable with results of this study.

The high hydraulic permeability can be explained by the presence of PVP in the polymer solution, which is associated with a better hydrophilicity, porosity and larger pore size in the membrane (Kanagaraj et al., 2015).

Table 1. PEI/PVP hollow fiber, clinical polysulfone and clinical polyethersulfone membrane transport properties and contact angles.

\begin{tabular}{|c|c|c|c|c|c|c|}
\hline Membrane & $\begin{array}{c}\text { Hydraulic } \\
\text { Permeability } \\
\text { (L/h.m².bar) }\end{array}$ & $\begin{array}{c}\text { Rejection } \\
\text { Coefficient (\%) } \\
\text { Lysozyme }\end{array}$ & $\begin{array}{c}\text { Rejection } \\
\text { Coefficient (\%) } \\
\text { Albumin (BSA) }\end{array}$ & $\begin{array}{l}\text { UR } \\
(\%)\end{array}$ & $\begin{array}{l}\text { Clearance } \\
(\mathrm{mL} / \mathrm{min})\end{array}$ & $\begin{array}{c}\text { Contact angle* } \\
\left({ }^{\circ}\right)\end{array}$ \\
\hline PEI/PVP & $67.4 \pm 2.1$ & $55.6 \pm 4,4$ & $95.7 \pm 0.6$ & 5.9 & 26.6 & $76.54 \pm 4.96$ \\
\hline Clinical PSf & $8.2 \pm 1.2$ & $92.0 \pm 2.6$ & $94.8 \pm 0.7$ & 4.0 & 55.8 & 64.3 \\
\hline Clinical PES & $137.5 \pm 0.8$ & $0.8 \pm 1.1$ & $2.7 \pm 0.4$ & 12.4 & 18.0 & 70.0 \\
\hline
\end{tabular}

*Contact angle of PEI/PVP data refer to flat sheet membranes. For PES and PSf membranes, the values were reported in the literature (Kaleekkal et al., 2015; Wenten et al., 2016).
As for the rejection coefficient of lysozyme and albumin, it is observed that the synthesized membranes present a good combination between the removal of lysozyme (and hence, very probably, of $\beta_{2}$-microglobulin) and albumin retention. Compared to clinical membranes, it is noted that the low flux PSf clinical membrane show a desirable high albumin retention, but exhibited the undesirable low removal of lysozyme. On the other hand, the high flux clinical PES membrane showed the opposite, with high removal of lysozyme, but at the same time, a great loss of albumin. The hollow fiber synthesized in this study showed a better performance for the rejection of uremic solutes $(55.6 \%$ for lysozyme and $95.7 \%$ for albumin), which may indicate a good potential for its use in hemodialysis treatment. An explanation for these results can be attributed to the pore size distribution in the membrane structure: a uniform pore size distribution allows a better discrimination among solutes of relatively close molecular weight. This fact justifies the good removal of lysozyme concomitant with albumin retention.

Santos et al. (2017) obtained a rejection coefficient of $89 \%$ for lysozyme and $99 \%$ for albumin in tests performed with flat sheet PEI/PVP membranes. The coefficient of rejection of lysozyme in the present study with hollow fibers is improved.

The transport rate of urea through the PEI/PVP hollow fibers in dialysis tests was comparable to those observed with low flux clinical membranes. Urea removal values were relatively low in all tests because they were performed using permeation modules with small membrane area $\left(60 \mathrm{~cm}^{2}\right)$ and also due to decrease of the driving force for transport, as the urea concentration in the dialysate increases in the batch experimental set up for this particular evaluation.

Urea clearance results for PEI/PVP membranes were also comparable to clinical membranes. Comparing the hydraulic permeability with clearance, it is observed that a high hydraulic permeability is not always associated with a high clearance of urea. This may be associated with the distribution of pores in the membranes. A uniform pore distribution allows diffusion of the urea molecules, provided the pore size is larger than the size of the molecule. However, membranes that have very large and very small pores can hinder the diffusion of the molecules, even if their 
hydraulic permeability is high. In the literature, some studies show no difference in results between the use of low or high flow membranes (Eknoyan et al., 2002; Cheung et al., 2003), while others report that high flow membranes are actually more efficient (Munshi and Ahmad, 2014; Woods and Nandakuman, 2000). In general, high flux membranes elevate the clearance of medium and large molecules, but do not have the same correlation for small molecules.

\section{Surface chemistry}

Figure 6 shows the spectrum obtained for PEI/PVP membranes. The PEI membrane spectrum exhibits absorptions of the imide group at $1780 \mathrm{~cm}^{-1}$ and 1720 $\mathrm{cm}^{-1}$, typical of the symmetrical and asymmetric stretch of the carbonyl groups present in the imide group; at $1355 \mathrm{~cm}^{-1}$ and $743 \mathrm{~cm}^{-1}$, referring to $\mathrm{C}-\mathrm{N}$ stretch and bend; and $1234 \mathrm{~cm}^{-1}$, typical of C-O-C aromatic ether. Similar results are reported in the literature (Santos et al., 2017; García et al., 2017; Chen et al., 2006).

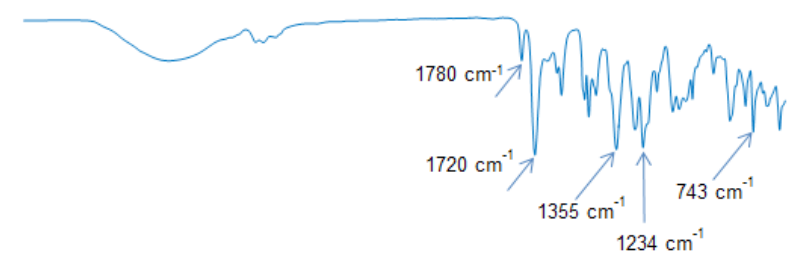

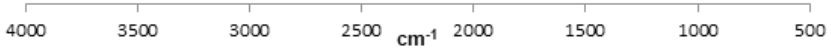

Figure 6. FTIR spectra PEI/PVP membranes surface.

\section{Hydrophilicity and zeta potential}

To evaluate the hydrophilicity of the PEI/ PVP hollow fiber, water uptake experiments were performed. Absorption of $3.9 \pm 0.4 \mathrm{mg}$ of water per $\mathrm{mg}$ of membrane was obtained. The occurrence of water absorption is an indication that synthesized hollow fibers are hydrophilic. Hydrophilicity is an important characteristic of hemodialysis membranes, because hydrophilic membranes are less likely to exhibit protein adsorption and platelet adhesion phenomena during hemodialysis treatment, and consequently, may have better blood compatibility.

In this study, we used the water uptake as an indirect measurement of membrane hydrophilicity, because contact angle measurements wetting the surface of microporous materials resulted in total intrusion of water, leading therefore to non-reliable data. In Table 1 , the contact angle of flat sheet PEI/PVP membranes (synthesized from a casting solution with the same composition as the hollow fiber PEI/PVP membranes) showed a contact angle of $76.5^{\circ}$. This result can indicate that PEI/PVP membranes are hydrophilic (as contact angle is less than $90^{\circ}$ ), confirming what was observed in the water uptake tests.

The determination of the zeta potential values in $1 \mathrm{mM} \mathrm{KCl}$ solution of the PEI/PVP membranes were performed from measurements based on the flow potential and the results are shown in Figure 7. From the behavior of the zeta potential, as a function of $\mathrm{pH}$, it is observed that the PEI/PVP membrane presents a negative charge throughout the analyzed $\mathrm{pH}$ range, and this negative charge decreases as the $\mathrm{pH}$ decreases.

Similar behavior of the zeta potential as a function of $\mathrm{pH}$ was also observed in the literature by Seifert et al. (2002), who evaluated the zeta potential of PEI membranes in the $\mathrm{pH}$ range of approximately 4 to 9 and found that, throughout this range, the zeta potential presents a negative charge, which decreases as the $\mathrm{pH}$ decreases, as in the results obtained this study. The negative charge could be attributed to the hydroxide ion adsorption/desorption processes, as one can interpret the decrease of zeta potential with the increase of $\mathrm{pH}$ (Neffe et al., 2014).

The negative charge showed by the hollow fibers along a large $\mathrm{pH}$ range may confer antithrombogenic properties to the material, because the phenomena of protein adsorption and platelet adhesion can be reduced.

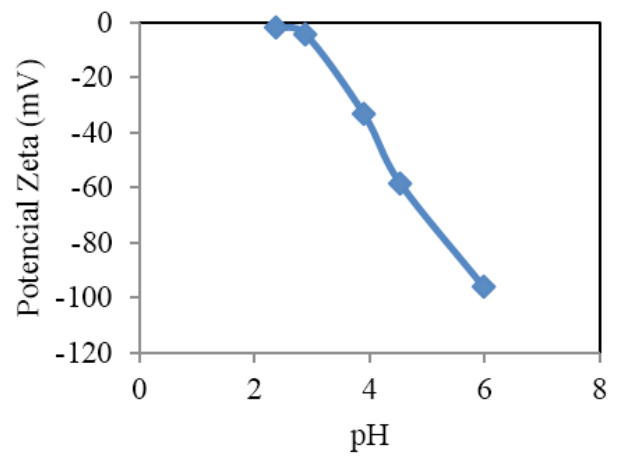

Figure 7. Zeta potencial of PEI/PVP membranes.

\section{Protein adsorption}

Results of the protein adsorption tests are shown in Figure 8. Albumin adsorption was approximately $0.32 \mathrm{mg} / \mathrm{mg}$ membrane for PEI/PVP membrane, 0.41 $\mathrm{mg} / \mathrm{mg}$ for the clinical PES and $0.20 \mathrm{mg} / \mathrm{mg}$ for the clinical PSf membrane. These results are in agreement with data reported in the literature, as presented by Roesink et al. (1991), who observed an adsorption of approximately $0.35 \mathrm{mg}$ of albumin per $\mathrm{mg}$ of a PEI/ PVP membrane, starting with an albumin solution of initial concentration of $40 \mathrm{~g} / \mathrm{L}$. The low protein adsorption exhibited by PEI/PVP membranes could be attributed to the hydrophilicity of the material (Ronco et al., 2017).

The deposition of proteins on the surface and in the pores of the membranes can affect the biocompatibility, and may be followed by the activation of several 


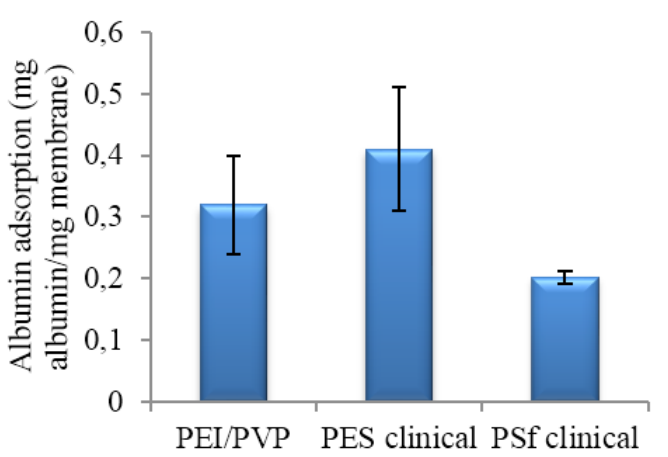

Figure 8. Albumin adsorption on membrane surfaces.

defense systems in the blood, such as coagulation, complement and fibrinolysis, as well as adhesion and activation of blood cells (Sun et al., 2003). Protein adsorption is considered the first stage of the blood clotting phenomenon.

The results observed for the synthesized membranes were comparable to those of the clinical polyethersulfone membranes, indicating that the polyetherimide/polyvynilpyrrolidone membranes are suitable for the intended application, with a hemocompatibility behavior similar to membranes used clinically in the renal treatment.

\section{CONCLUSIONS}

High flux PEI/PVP hollow fibers were successfully synthesized and characterized aiming at alternative materials for hemodialysis membranes. The membranes presented an efficient removal of lysozyme and a concomitant albumin retention, showing better results than membranes currently used in clinical treatments. The results of urea removal and clearance were also comparable to those of the membranes of clinical dialyzers. In addition, biocompatibility as revealed by hydrophilicity, zeta potential and protein adsorption evaluations, strongly indicate that the PEI/ PVP hollow fibers are good candidates for application in hemodialysis.

\section{ACKNOWLEDGEMENTS}

To CNPq and FAPERJ for financial support.

\section{NOMENCLATURE}

\begin{tabular}{|c|c|}
\hline $\mathrm{J}$ & Water flux (L/h) \\
\hline $\mathrm{L}_{\mathrm{p}}$ & Hydraulic permeability (L/h.m².bar) \\
\hline$\Delta \stackrel{p}{\mathrm{P}}$ & $\begin{array}{l}\text { Pressure difference between feed solution } \\
\text { and the permeate (bar) }\end{array}$ \\
\hline $\mathrm{R}$ & Rejection coefficient $(\%)$ \\
\hline $\mathrm{C}_{\mathrm{A}}^{\mathrm{c}}$ & $\begin{array}{l}\text { Feed concentration in the ultrafiltration test } \\
(\mathrm{mg} / \mathrm{L} \text { or } \mathrm{mmol} / \mathrm{L})\end{array}$ \\
\hline $\mathrm{C}_{\mathrm{P}}$ & $\begin{array}{l}\text { Permeate concentration in the ultrafiltration } \\
\text { test }(\mathrm{mg} / \mathrm{L} \text { or } \mathrm{mmol} / \mathrm{L})\end{array}$ \\
\hline UR & Urea removal $(\%)$ \\
\hline
\end{tabular}

$\mathrm{C}_{\mathrm{UF}} \quad$ Concentration of post-dialysis urea $(\mathrm{mg} / \mathrm{L})$

$\mathrm{C}_{\mathrm{UI}} \quad$ Concentration of pre-dialysis urea $(\mathrm{mg} / \mathrm{L})$

$\mathrm{c}(\mathrm{t})$ Concentration of urea at time $t$ in the dialysis test $(\mathrm{mg} / \mathrm{L})$

$\mathrm{c}_{0} \quad$ Initial concentration of urea $(\mathrm{mg} / \mathrm{L})$

$\mathrm{t} \quad$ Time (min)

$\mathrm{Cl} \quad$ Clearance of urea $(\mathrm{mL} / \mathrm{min})$

$\mathrm{V}(\mathrm{t}) \quad$ Volume in the system at time $\mathrm{t}(\mathrm{mL})$

$\Delta \varphi \quad$ Flow potential $(\mathrm{mV})$

$\Delta \mathrm{P}_{\mathrm{z}} \quad$ Pressure applied to the cell to force the electrolyte to flow on the charged surface (mbar)

$\varepsilon_{0} \quad$ Vacuum permittivity (As / Vm)

$\varepsilon_{\mathrm{r}} \quad$ Relative dielectric constant of the solvent of the electrolyte

$\varsigma \quad$ Zeta potential $(\mathrm{mV})$

$\eta \quad$ Dynamic viscosity of the electrolyte (mPa.s)

$\lambda_{0} \quad$ Electrical conductivity of the circulating electrolyte $(\mathrm{mS} / \mathrm{m})$

$\lambda_{\mathrm{h}} \quad$ Electrical conductivity of the electrolytic solution $(\mathrm{mS} / \mathrm{m})$

$\mathrm{R}_{\mathrm{h}} \quad$ Electrical resistance measured through the flow channel

$\mathrm{R} \quad$ Electrical resistance measured through the channel under normal experimental conditions

$\mathrm{m}_{\mathrm{i}} \quad$ Initial quantity of albumin in solution in the adsorption test

$\mathrm{m}_{\mathrm{f}} \quad$ Quantity of albumin in solution after the time of contact with the membrane in the adsorption test

$\mathrm{m}_{\text {membrane }}$ Quantity of membrane packed in glass tubes in the adsorption test

\section{REFERENCES}

Chen, B. K., Su, C. T., Tseng, M. C., Tsay, S. Y. Preparation of Polyetherimide Nanocomposites with Improved Thermal, Mechanical and Dielectric Properties. Polymer Bulletin, 57, 671-681 (2006). https://doi.org/10.1007/s00289-006-0630-3

Cheung, A. K., Levin, N. W., Greene, T., Agodoa, L., Bailey, J., Beck, G., Rocco, M. V. Effects of Highflux Hemodialysis on Clinical Outcomes: Results of the HEMO Study. Journal of the American Society of Nephrology, 14, 3251-3263 (2003). https://doi. org/10.1097/01.ASN.0000096373.13406.94

Eknoyan, G., Beck, G. J., Cheung, A. K., Daugirdas, J. T., Greene, T., Kusek, J. W., Dwyer, J. T. Effect of Dialysis Dose and Membrane Flux in Maintenance Hemodialysis. New England Journal of Medicine, 347, 2010-2019 (2002). https://doi.org/10.1056/ NEJMoa021583

García, M. G., Marchese, J., Ochoa, N. A. Improved Gas Selectivity of Polyetherimide Membrane by the Incorporation of PIM Polyimide Phase. Journal of Applied Polymer Science, 134 (2017). https:// doi.org/10.1002/app.44682 
Hurwitz, G., Guillen, G. R., Hoek, E. M. V. Probing Polyamide Membrane Surface Charge, Zeta Potential, Wettability, and Hydrophilicity with Contact Angle Measurements. Journal of Membrane Science, 349, 349-357 (2010). https:// doi.org/10.1016/j.memsci.2009.11.063

Kaleekkal, N. J., Thanigaivelan, A., Tarun, M., Mohan, D. A functional PES membrane for hemodialysis - Preparation, Characterization and Biocompatibility. Chinese Journal of Chemical Engineering, 23, 1236-1244 (2015). https://doi. org/10.1016/j.cjche.2015.04.009

Kanagaraj, P., Nagendran, A., Rana, D., Matsuura, T., Neelakandan, S., Malarvizhi, K. Effects of Polyvinylpyrrolidone on the Permeation and Fouling-Resistance Properties of Polyetherimide Ultrafiltration Membranes. Industrial \& Engineering Chemistry Research, 54, 4832-4838 (2015). https://doi.org/10.1021/acs.iecr.5b00432

Maduell, F., Varas, J., Ramos, R., Martin-Malo, A., Pérez-Garcia, R., Berdud, I., Moreso, F., Canaud, B., Stuard, S., Gauly, A., Aljama, P., Merello, J. I. Hemodiafiltration Reduces All-Cause and Cardiovascular Mortality in Incident Hemodialysis Patients: a Propensity-Matched Cohort Study. American Journal of Nephrology, 46, 288-297 (2017). https://doi.org/10.1159/000481669

Munshi, R., Ahmad, S. Comparison of Urea Clearance in Low-efficiency Low-flux vs. High-efficiency High-flux Dialyzer Membrane with Reduced Blood and Dialysate Flow: An in Vitro Analysis. Hemodialysis International, 18, 172-174 (2014). https://doi.org/10.1111/hdi.12054

Neffe, A. T., Ruesten-Lange, M. von, Braune, S., Lützow, K., Roch, T., Richau, K., Krüger, A., Becherer, T., Thünemann, A. F., Jung, F., Haag, R., Lendlein, A. Multivalent grafting of hyperbranched oligo- and polyglycerols shielding rough membranes to mediate hemocompatibility. Journal of Materials Chemistry B, 2, 3626-3635 (2014). https://doi.org/10.1039/C4TB00184B

Nubé, M. J., Peters, S. A., Blankestijn, P. J., Canaud, B., Davenport, A., Grooteman, M. P., Asci, G., Locatelli, F., Maduell, F., Morena, M., Ok, E., Torres, F., Bots, M. L. Mortality Reduction by Post-Dilution OnlineHaemodiafiltration: a Cause-Specific Analysis. Nephrology Dialysis Transplantation, 32, 548-555 (2016). https://doi.org/10.1093/ndt/gfw381

Oshvandi, K., Kavyannejad, R., Borzuo, S. R., Gholyaf, M. High-flux and Low-flux Membranes: Efficacy in Hemodialysis. Nursing and Midwifery Studies, 3 (2014). https://doi.org/10.17795/nmsjournal21764

Pereira, C. C., Nobrega, R., Borges, C. P. Spinning Process Variables and Polymer Solution Effects in the Die-Swell Phenomenon during Hollow Fiber Membranes Formation. Brazilian Journal of Chemical Engineering, 17, 599-606 (2000). https:// doi.org/10.1590/S0104-66322000000400024
Roesink, H. D. W., Beerlage, M. A. M., Potman, W., Boomgaard, T. van den, Mulder, M. H. V., Smolders, C. A. Characterization of New Membrane Materials by Means of Fouling Experiments Adsorption of BSA on Polyetherimide - Polyvinylpyrrolidone Membranes. Colloids and Surfaces, 55, 231243 (1991). https://doi.org/10.1016/01666622(91)80095-6

Ronco, C.; Neri, M., Lorenzin, A., Garzotto, F., Clark, W. R. Multidimensional Classification of Dialysis Membranes, Expanded Hemodialysis. Karger Publishers, 115-126 (2017). https://doi. org/10.1159/000479260

Santos, A. M. dos, Habert, A. C., Ferraz, H. C. Development of Functionalized Polyetherimide/ Polyvinylpyrrolidone Membranes for Application in Hemodialysis. Journal of Materials Science: Materials in Medicine, 28, 131 (2017). https://doi. org/10.1007/s10856-017-5946-z

Seifert, B., Mihanetzis, G., Groth, T., Albrecht, W., Richau, K., Missirlis, Y., Paul, D., Sengbusch, G. von, Polyetherimide: a New MembraneForming Polymer for Biomedical Applications. Artificial Organs, 26, 189-199 (2002). https://doi. org/10.1046/j.1525-1594.2002.06876.x

Stamatialis, D. F., Papenburg, B. J., Girones, M., Saiful, S., Bettahalli, S. N., Schmitmeier, S., Wessling, M. Medical Applications of Membranes: Drug Delivery, Artificial Organs, and Tissue Engineering. Journal of Membrane Science, 308, 1-34 (2008). https://doi.org/10.1016/j.memsci.2007.09.059

Sun, S., Yue, Y., Huang, X., Meng, D. Protein Adsorption on Blood-Contact Membranes. Journal of Membrane Science, 222, 3-18 (2003). https:// doi.org/10.1016/S0376-7388(03)00313-2

Tan, W., Wang, Q., Xin, G., Wang, Y., Liu, F., He, C., Xu, X. Different Hemodialysis Methods for Survival of Patients with Maintenance Hemodialysis: a MetaAnalysis. International Journal of Clinical and Experimental Medicine, 11, 4389-4396 (2018).

Ward, R. A. Protein-Leaking Membranes for Hemodialysis: A New Class of Membranes in Search of an Application? Journal of the American Society of Nephrology, 16, 2421-2430 (2005). https://doi.org/10.1681/ASN.2005010070

Wechs, F., Gehlen, A., Harten, B. von, Kruger, R., Schuster, O. Dialysis Membrane with Improved Removal of Middle Molecules. Patent Number US $8,651,284$ B2 (2014).

Woods, H. F., Nandakumar, M. Improved Outcome for Haemodialysis Patients Treated with High-flux Membranes. Nephrology Dialysis Transplantation, 15, 36-42 (2000). https://doi.org/10.1093/ oxfordjournals.ndt.a027962

Wenten, I. G., Aryanti, P. T. P., Khoiruddin, K., Hakim, A. N., Himma, N. F. Advances in polysulfonebased membranes for hemodialysis. Journal of Membrane Science and Research, 2, 78-89 (2016). 